\section{Autoantikörper gegen IgA}

W. Stöcker

Euroimmun Medizinische Labordiagnostika AG, Lübeck, Deutschland

\section{Synonym(e) Anti-IgA}

Englischer Begriff autoantibodies against $\operatorname{IgA}$; anti-IgA antibodies

Definition Autoantikörper gegen IgA richten sich gegen Immunglobuline der Klasse IgA, sie können prinzipiell allen Immunglobulinklassen angehören, auch der Klasse IgA selbst. Es handelt sich allerdings in den meisten Fällen nicht um Autoantikörper im eigentlichen Sinne, sondern um $>$ Alloantikörper, da zumindest bei absolutem IgA-Mangel dieses Immunglobulin nicht zum Autoantigenrepertoire gehört.

Funktion - Pathophysiologie Wirkliche Autoantikörper gegen IgA kommen sehr selten vor, sie wirken sich in gleicher Weise aus wie durch Immunisierung IgA-defizienter Personen induzierte Antikörper gegen $\operatorname{IgA}$, wie sie häufig bei Personen mit absolutem oder relativem selektiven IgAMangel nach parenteraler Verabreichung von Blut oder Blutbestandteilen gefunden werden. Die Reaktion gegen das IgA erneut verabreichten Spenderbluts kann bei diesen Personen schwere nicht hämolytische Transfusionsreaktionen auslösen.

Untersuchungsmaterial Serum, Plasma.

Probenstabilität Autoantikörper sind bei $+4{ }^{\circ} \mathrm{C}$ bis zu 2 Wochen lang beständig, bei $-20^{\circ} \mathrm{C}$ über Monate und Jahre hinweg.
Analytik Die meisten Anti-IgA-Autoantikörper gehören der Immunglobulinklasse IgG an. Der Nachweis geschieht in der Regel durch passive Hämagglutination.

Ein empfindlicher $>$ Enzyme-linked Immunosorbent Assay ist in der Lage, entsprechende Autoantikörper auch in geringer Konzentration bei Normalpersonen ohne Immunglobulindefizienz nachzuweisen. Dabei wird zur Beschichtung der Festphase aus mehreren Myelomseren gewonnenes und hochgereinigtes $\operatorname{Ig}$ A über Streptokokken-Protein B an die Oberfläche gebunden.

Referenzbereich - Erwachsene Negativ.

Referenzbereich - Kinder Negativ.

Indikation Abklärung einer Transfusionsreaktion, Vorbereitung einer Transfusion.

Diagnostische Wertigkeit Autoantikörper gegen IgA werden bei $20 \%$ der Patienten mit relativem IgA-Mangel (Werte unter $5 \mathrm{mg} / \mathrm{dL}$ ) gefunden, liegt gleichzeitig ein systemischer Lupus erythematodes vor, beträgt die Prävalenz nahezu $100 \%$.

Bei Kaukasiern wird für den selektiven IgA-Mangel eine Prävalenz von 1:500-1:100 angegeben. Die oft damit assoziierten Autoantikörper gegen IgA haben für die betroffenen Personen normalerweise keine negativen Folgen, abgesehen von der Möglichkeit schwerer Transfusionsreaktionen.

Ist eine Transfusion bei Patienten mit Anti-IgA-Antikörpern erforderlich, müssen in jedem Fall gewaschene Erythrozytenkonzentrate verabreicht werden.

\section{Literatur}

Cunningham-Rundles C (1996) IgA Autoantibodies. In: Peter JB, Shoenfeld Y (Hrsg) Autoantibodies. Elsevier, Amsterdam, S 417-422

Strober W, Wochner RD, Barlow MH et al (1968) Immunoglobulin metabolism in ataxia telangiectasia. J Clin Invest 47:1905-1915 